\title{
MEMORY-EXPERIENCE GAP IN EARLY ADOLESCENTS' HAPPINESS REPORTS
}

\author{
Maja Tadic, Huub Braam, Katja VanVliet, Ruut Veenhoven \\ In: Child Indicator Research, DOI 10.1007/s12187-013-9194-6 \\ Accepted: 7 April 2013 ISSN 1874-8988
}

\begin{abstract}
Studies among adult populations show that estimates of how happy one has felt in the past tend to be more positive than average happiness as assessed using time sampling techniques. This 'memory-experience gap' is attributed to cognitive biases, among which fading affect bias. In this paper we report a study among 352 pupils of a secondary school in the Netherlands. These youngsters reported subsequently: 1) how happy they had felt yesterday, 2) how happy they had felt during the last month, 3) what they had done the previous day and 4) how they had felt during each of these activities. Unlike earlier studies, the average rating of happiness in the last month appeared to be lower than average happiness of the previous day. In accordance with earlier research, the global rating of happiness during the previous day was higher than the average of reported affect during separate activities during that day. A further multilevel analysis suggest that in estimating how they have felt on the whole yesterday, youngsters overestimated short pleasant episodes and underestimated unpleasant episodes, especially when such episodes lasted long.
\end{abstract}

Keywords: Happiness measurement, Day Reconstruction Method (DRM), Adolescents, Retrospection

\section{INTRODUCTION}

Scientific interest in happiness has expanded greatly during the past decade: The Bibliography of Happiness contains over 6700 publications to which some 400 titles are added each year (Veenhoven 2011).

Among those publications, 154 are on Erasmus University, Rotterdam, Netherlands happiness of children and adolescents (e.g., Gilman and Huebner 2003; Huebner 2004; Huebner et al. 2000, 2006; Lee 2003).Studies among adult populations show that estimates of how happy one has felt in the past tend to be more positive than average happiness as assessed via multimoment episodic measures (Miron-Shatz et al. 2009). This 'memory-experience gap' is attributed to cognitive biases, among which fading affect bias (Thompson et al. 1996; Walker et al. 2003). and the specifics of experiencing and recalling emotional states (accessibility model of emotional self-report, Robinson and Clore 2002).

M. Tadic

Institute of Social Sciences Ivo Pilar, Marulicev trg 19/1, 10000 Zagreb, Croatia e-mail: maja.tadic@pilar.hr

H. Braam , K. Van Vliet

Verwey-Jonker Institute, Utrecht, Netherlands

R. Veenhoven

Erasmus University Rotterdam, Faculty of Social Sciences,

P.O.B. 17383000 DR Rotterdam, Netherlands and North-West University in South Africa 
Bearing in mind that assessments of happiness among children and adolescents mostly relied on global retrospective cognitive estimates, whilst multi-moment assessments of affect have been used in only a few studies (e.g., Larson et al. 2002; Lee 2003; Silk et al. 2003), in order to gain more understanding on the validity of children's and early adolescents' happiness reports, the memoryexperience gap requires further examination in that population.

Therefore, the central aim of this study was to examine the memory-experience gap in happiness reports among early adolescents. More concretely, using the day reconstruction methodology (DRM, Kahneman et al. 2004; Miron-Shatz et al. 2009), we examined the differences between retrospective overall happiness reports of the previous day and average happiness felt during specific daily activities in the same day among early adolescents. In addition, we also examined the role of duration and the hedonic level (valence) of affect of those activities in explaining the memory- experience gap.

\section{CHILDREN'S AND ADOLESCENTS HAPPINESS ASSESMENT}

Although the attempts to accurately capture children's happiness is not new, there is a growing attention to the field in recent literature (e.g. Ben Arieh 2008; Gilman and Huebner 2000, 2003). Some of research lines emphasize the importance of investigating the overall well-being of children's and adolescents' lives. For instance, Bradshaw and Richardson (2009) have recently proposed a broad child well-being index that refers to well-being as an overall evaluation of children's lives that cannot be represented by a single indicator because each aspect of their lives each has an influence on their well-being (Ben-Arieh et al. 2001). Their index encompasses health, subjective well-being, personal relationships, material resources, education, behavior and risks, housing and the environment.

In most cases, these indexes have the goal to capture the differences and changes in wellbeing across nations, as indicators of impact of various life events, circumstances and cultural variations. As such, these broad indexes of the overall well-being of children's and adolescents' lives provide a lot of understanding of the interrelations of various circumstances of their lives and their subjective experiences of their lives.

However, many of the existing scales and indexes do not take children's views and experiences into account; rather they typically use parents, family or household as the unit of analysis, and recent progress in child well-being measures recognized that it is necessary to ask children directly about their how much they like the lives they lead (Ben-Arieh 2008; Bradshaw and Richardson 2009; McCauley 2012). Moreover, most of these indexes and scales refer to global retrospective measures of either objective circumstances and/or cognitive aspects of wellbeing, and some of them still require more testing and developing in order to make them reliable (Bradshaw and Richardson 2009).

Altogether, although these types of measures have shown to yield useful information, they have also been associated with several specific limitations. For instance, Gilman and Huebner (2000) showed that existing life satisfaction scales for adolescents meet the standards for research only when less rigid psychometric standards are applied. Similarly, questions on adolescents' global life satisfaction may also be vulnerable for social desirability bias and impression management, because of greater conformity to peer group pressure (Gilman and Huebner 2000). Therefore, in order to gain more insight into the finely grained processes of subjective experiences of children's lives, in this study we focus on the self-assessment and the subjective experience of early adolescents' lives as indicators of happiness. 


\section{HAPPINESS AND ITS COMPONENTS}

The current study defines happiness as subjective enjoyment of life: The degree to which an individual judges the overall quality of his or her life-as-a-whole favorably (Veenhoven 1984,2009). In order to assess overall quality of their lives, people typically rely on two different types of information: how well they feel most of the time and how well they meet common standards of the good life (Robinson and Clore 2002). Thus, overall happiness draws on two subappraisals: an affective component called hedonic level of affect, and a cognitive component called contentment (Veenhoven 2009).

Whereas contentment refers to the degree to which one perceives that his or her wants in life are fulfilled, hedonic level of affect is the degree to which positive affective experience outweighs negative ones (Pavot and Diener 2008). In other words, people seem to experience different levels of happiness in their daily lives, but they also possess generalized beliefs about their happiness (Robinson and Clore 2002 ; Veenhoven 2009). Contentment is typically assessed using global questions such as: "On the whole, my life is close to how I would like it to be. Please rate the degree to which you agree with this sentence ranging from strongly disagree (1) strongly agree (5)") (e.g. Kahneman and Deaton 2010).

The ability to answer such questions requires complex cognitive activities, such as retrospection on what one wants and what one has, and intraindividual and interindividual comparison (Pavot and Diener 2008; Schwarz et al. 2009). As such, these retrospective types of assessments have proven to be susceptible to various biases (Kahneman and Krueger 2006; Krueger and Schkade 2008; Robinson and Clore 2002; Schwarz et al. 2009). Hedonic level of affect can be measured in two ways. One way is to use global assessments, such as a common question: "On the whole, how do you feel most of the time? Please choose your answer on a scale from bad (1) to good (5)". Answering this question also requires retrospection. However, another way to capture hedonic level of affect is to use real-time multimoment assessments, such as the Experience Sampling Method (ESM) or diary methodology (such as The Day Reconstruction Method, DRM; Kahneman et al. 2004). These methods do not require retrospection, and, as such, are less susceptible to various biases (Kahneman, et al. 2004; Scollon et al. 2009). In this study we focus on hedonic level of affect as assessed via diary methods.

The distinction between contentment and hedonic level of affect is particularly relevant for children and early adolescents. Specifically, bearing in mind that early adolescents may have not yet developed clear cognitive standards of the good life and are not yet entirely able to judge life as they are lacking a clear view on standard (Dahl 2004; Yurgelun-Todd 2007), global cognitive assessments of happiness may not be the optimal measures of well-being for that particular population.

\section{RETROSPECTIVE AND EPISODIC HAPPINESS ASSESSMENT: THE MEMORY- EXPERIENCE GAP}

Growing research evidence documents incongruence between people's concurrent (episodic) and 
retrospective reports of emotional experience (Miron-Shatz et al. 2009; Schwarz et al. 2009). For example, studies among large samples of adults showed that the overall daily ratings of affect are significantly higher than those based on episodic multi-moment assessments captured via the DRM (DRM; Dockray et al. 2010; Kahneman et al. 2004; Stone et al. 2006).

That difference between the average of episodic affective states reports and the retrospective global evaluation of the same affective experience has been conceptualized as the memory-experience gap (MEG; Miron-Shatz et al. 2009). This memory- experience gap has been demonstrated in different aspects of peoples' affective experiences, such as happiness (Miron-Shatz et al. 2009), coping (Todd et al. 2004), vacations (Kemp et al. 2008; Wirtz et al. 2003), and pain (Redelmeier et al.2003; Stone and Broderick 2007). These findings provided further support for the conceptual and methodological distinction of contentment and hedonic level of affect as two different aspects of well-being.

Altogether, existing research evidence implies that the common global retrospective selfestimates might not be the optimal way of measuring happiness among children and adolescents because they refer to cognitive evaluations of life. To answer these types of assessments, children have to employ both memory and complex judgment processes that include how they feel in their life, which includes many moments. Thus, children have to summarize those momentary feelings into a meaningful evaluation, which is related to substantial retrospective biases even among adults (e.g. Kahneman et al. 2004).

By using cognitive retrospective measures as indicators of happiness, we risk overestimating how happy children and early adolescents are (Kahneman and Krueger 2006; Miron-Shatz et al. 2009; Robinson and Clore 2002). Episodic (multi-moment) assessments of mood of the moment, such as DRM, might provide more accurate view of how happy a child or an early adolescent is, because those types of measures aim at how they feel at specific moments instead of how they think they feel in general (Ciarrochi et al. 2008).

\section{THE PRESENT STUDY}

The current study had two main goals. First, the major goal was to examine whether MEG is present in happiness ratings among early adolescents. In doing so, we also aimed to examine the distribution of the MEGs according to their size and valence. Specifically, although previous studies showed that the retrospective evaluation of the affective experience is usually more positive than the averaged episodic emotions, there are also exceptions: There also seem to be cases of underestimation of the hedonic affect level (Miron-Shatz et al. 2009; Walker et al. 2003).

Thus, the second aim of our study was to examine the potential sources for these variations. Based on the fading affect bias framework (Walker et al. 1997, 2003), we expected that these variations might be related to the valence of the affective experiences (pleasant vs. unpleasant). More concretely, when recalling the affect felt during specific episodes in one's recent past, it is possible that people tend to overestimate their positive experiences, whilst underestimating the negative experiences. In other words, we aimed to see whether the less pleasant affect episodes would more "distant" from the overall retrospective daily hedonic valence reports than more pleasant affect episodes.

In order to examine the memory-experience gap in happiness reports among early adolescents, we employed a DRM research design (Kahneman et al. 2004). The study was conducted among 352 pupils of secondary schools in the Netherlands, and these youngsters reported: 1) how happy in the overall they had felt yesterday, 2) what they had done yesterday (episodes of daily activities), 3) how long these episodes lasted, and 4) how they had felt during each of these episodes (episodic hedonic level of affect). 
The DRM aims to assess participants' affective states felt during their daily activities. In that way, DRM attempts to invoke the actual context of a person's experience, as opposed to the semantic and decontextualized way of remembering that involves one's beliefs, attitudes and personal aspirations about emotions (Miron- Shatz et al. 2009; Robinson and Clore 2002). As such, DRM reports are closely tied to situations and are less influenced by memory biases than global reports of emotions and moods (Diener and Tay 2013; Dockray et al. 2010).

Previous research documented close congruence of happiness reports obtained via the DRM and happiness reports obtained in real-time, such as those using the Experience Sampling Method (ESM; Dockray et al. 2010; Kahneman et al. 2004). However, compared to experience sampling method, DRM has fewer burdens on the participants, while still providing an assessment of continuous episodes over the course of the full day (Diener and Tay 2013). In that way, the DRM design enabled us to analyze the differences in global and episodic measures of hedonic level of affect - the affective component of happiness. Moreover, it enabled us to examine the role of duration in the relationship between the hedonic level of affect and the size of the memory-experience gap.

Building upon previous findings on adult population (e.g. Miron-Shatz et al. 2009), we assumed the same pattern of retrospective overestimation of affective experiences will be present in happiness reports among adolescents. Specifically, we expected that the global daily ratings of early adolescents' hedonic level of affect will be significantly higher than the average of episodic multi-moment assessments captured via the DRM. Stated in a more formal way, we conceptualized our first hypothesis:

Hypothesis 1. When asked to rate how happy they felt yesterday in the overall, adolescents will give higher overall daily happiness ratings than their averaged activity-based happiness report indicates. However, we also expected that there will be substantial variations in MEGs, namely, we expect that when recalling the affect felt during specific episodes during the previous days, pupils will overestimate their positive experiences, whilst underestimating the negative experiences. Specifically, our memory system seems to have different strategies for the recollection of negative and positive affect: Previous research has demonstrated that people's recollections of the past are often positively biased (Walker and Skowronski 2009; Walker et al. 2003). For instance, using a longitudinal diary method, Walker et al. (1997) examined the recollection of emotional states related to events. The results demonstrated that judgments of pleasantness or unpleasantness of an event became less intensive with time, and this effect was larger for unpleasant events than for pleasant events.

This tendency of our memory system to fade out the affective intensity of memories with time, with negative affective experiences fading substantially faster than positive affective experiences, has been conceptualized as the fading affect bias (FAB; Walker et al. 2003). A recent study by Gibbons et al. (2011) has shown that this fading affect bias tends to not only increase over time (across 3-month, 9-month and 4.5-year intervals), but also that it is present even for the events occurring after 1 day, as well as on the test day. Hence, it is feasible to assume that FAB tendencies will be present in the event for the episodes that have occurred during the previous day.

Bearing in mind these research findings and theoretical considerations about the fading affect bias, we formulated our second hypothesis:

Hypothesis 2. The less pleasant an activity is, the bigger the gap between the retrospective overall and the episodic ratings of hedonic level of affect will be because we expect unpleasant experiences to fade more quickly and are thus less available for recall (Walker et al. 2003).

Furthermore, because affective experiences are inherently dynamic, as they unfold and change 
over time, their central time-related characteristic is their duration (Ariely 1998; Verduyn et al. 2009, 2012). The duration of an emotional episode can be defined as the period between its start and the moment it is no longer felt (Verduyn et al. 2012). As previous research shows, an affective state can last from only a couple of seconds up to several hours or longer (Fitness and Fletcher 1993; Schimmack et al. 2000; Verduyn et al. 2009).

Only a few recent studies have addressed some of the issues related to the duration of affective experiences. For example, in two experience sampling studies Verduyn et al. (2009) examined the prediction of the duration of emotional experience, and have showed that the higher the importance of the emotion-eliciting situation and the higher the intensity of the emotion at onset, the longer the emotional experience lasts.

Similarly, Sonnemans and Frijda (1995) found that the more important the situation that elicited the emotional experience, the longer the emotional experience will last. Also, Schimmack (2003) reported that the duration of unpleasant affect significantly correlates with personality traits: The correlation between the duration of unpleasant affect and extraversion was found to be negative, and the correlation between the duration of unpleasant affect and neuroticism was found to be positive.

In addition, a recent study by Verduyn et al. (2012) demonstrated that people are mostly accurate at estimating the duration of emotional stimuli, but that there is a tendency to somewhat overestimate the duration of relatively short emotional stimuli and slightly underestimate the duration of relatively long emotional stimuli. Moreover, their study showed that the estimates of the duration of emotions experienced during emotional stimuli closely correspond to actual emotional stimuli duration, all of which implies that people are capable of remembering the duration of their emotions in relatively accurate way.

Altogether, research findings indicate that the duration of affective episodes is a highly relevant aspect of affective experiences; hence, in order to gain more understanding on affective experiences, it is necessary to take this time-related aspect into account (e.g., Verduyn et al. $2009,2011)$. Therefore, we aimed to investigate the role of duration of an affective experience related to early adolescents' daily activities in the variance of the memory-experience gap. More concretely, we aimed to find out how does the duration interact with the hedonic level of affect in predicting the size of the memory-experience gap. On the one hand, as mentioned above, previous research showed that our memory system tends to fade out the memories of affective intensity with time, with intense negative emotional experiences fading much faster than intense positive emotional experiences. On the other hand, recent study revealed that people tend to overestimate the duration of relatively short emotional stimuli and slightly underestimate the duration of relatively long emotional stimuli (Verduyn et al. 2012).

Thus, building upon previous research on fading affect bias, and recent findings on the importance of the duration of affective experiences, we aimed to investigate if the pleasantness of affect experienced during the early adolescents' daily activities moderates the relationship between activity duration and the memory-experience gap on the activity level. To the best of our knowledge, this is the first study to examine the interaction between the duration and hedonic level of affect related to daily activities on different workdays; and in that way our study contributes to research on the validity of children and adolescents' well-being indicators. Based on previous findings and theoretical considerations, we state our third and final hypothesis:

Hypothesis 3. The pleasantness of affect experienced during the early adolescents' daily activities moderates the relationship between activity duration and the memory-experience gap on the activity level: When the duration of the activity is long, less pleasant activities are related to bigger gap, whereas more pleasant activities are related to lower gap. 


\subsection{Participants}

Participants were 352 Dutch pupils (172 boys and 180 girls) engaged in Lessons in Happiness project (Braam et al. 2008; Boerefijn 2010), within 12 secondary schools in The Netherlands. Participants age ranged from 12 to 15 years. The pupils are ethnically diverse, as it is the case in Dutch society, with most of them (81.5\%) reporting Dutch ethnicity, and $18.5 \%$ reporting Surinamese, Antilleans', Turkish, Moroccans or other ethnicity. The majority of pupils (77.9\%) reported living with both of their parents, whereas $20.3 \%$ stated they live with one of their parents, and $1.8 \%$ stated other forms of living arrangements.

\subsection{Procedure}

All of the pupils filled out the questionnaire on-line on a weekday in classrooms at their school. First, they were asked to give two global ratings of how happy they had felt yesterday, and how happy they had felt during the past month. Next, they were asked to fill out Yesterday's Diary (described in detail below), which is an internet application of the DRM (Kahneman et al. 2004), modified and developed by Veenhoven (2009) for this study.

The DRM is specially designed to reduce retrospective bias. It requires respondents to divide the previous day in chronologically ordered episodes (activities participants engaged in throughout the day), which fosters accurate recall. After having 'reconstructed' the day, participants rate how happy they have felt during each of the activities. DRM combines elements of time-budget measurement and experience sampling. Compared to ESM, DRM is easier to conduct, but it is still providing an assessment of continuous episodes over the course of the full day, rather than a sampling of moments (Kahneman and Krueger 2006; Stone et al. 2006).

\subsection{Measures}

The procedure involved the following measures:

\section{Retrospective Assessment of Hedonic Level of Affect}

We assessed the hedonic level of affect using two different time frames: First, we asked the "How happy did you feel during the previous day? ", and then "How happy did you feel during the past month? " Both questions were rated on a graphical response scale with faces ranging from 0 (extremely unhappy) to 10 (extremely happy), as presented in Figs. 1 and 2. The faces communicate that the focus is on affective experience.

\section{Episodic (multi-moment) Assessment of Hedonic Level of Affect}

Using Yesterdays' Diary, adolescents systematically reconstructed what they did and experienced during the previous day. First, each diary started with getting up and ended with going to bed, and pupils reported the types of activities they engaged in during the preceding day in a chronological order. Thereafter, pupils were directed to a second screen, which presented all of the activities they listed in a chronological order. Here, using the same graphical scale with faces as in the retrospective assessments described above; pupils rated how happy they felt during each of the reported activities.

\section{Daily Activities}

In current study, we refer to activities as behavioral practices in which pupils engage in daily life. They choose daily activities from a list that involved: getting up, eating, getting ready, being in school, doing homework, engaging in sport, relaxing with friends, relaxing alone (e.g. watching TV, surfing the Internet, reading a book), being with family, going to a club/church, doing house chores, visiting a doctor, going to bed). Pupils could also add other activities. 


\section{Activity Duration}

For each listed activity (e.g., studying, doing homework), boys and girls also stated the approximate times at which an activity began and ended. The duration in minutes of each activity was calculated from those beginning and ending times information.

\section{Background Variables}

After filling out Yesterdays' diary, adolescents responded to a background questionnaire on, sex, age, ethnicity, living arrangements, type of school and class they are attending at the moment.

\subsection{Data Analysis}

In order to address the research questions stated in Hypothesis 1, first we constructed a memoryexperience gap variable on a between-person level. Building upon previous studies (Miron-Shatz et al. 2009), we conceptualized memory-experience gap as the difference score between the retrospective (overall) report of the hedonic level of affect during yesterday and the aggregated episodic (activity-based) hedonic level of affect reports in that same day. We used one-sample $t$ test because it allows us to test whether a sample mean of the memory-experience gap (a normally distributed interval variable) significantly differs from zero.

In order to capture more fine grained processes on a within person-level, we also looked at the memory-experience gap on the within-person level, that is, we looked at the difference between hedonic level of affect related to each of the activities and the retrospective hedonic level of affect. This enabled us to examine whether episodic hedonic valence of affect is significantly associated with the size of the MEG, not just on a between-person, but also on a within-person level.

Because this dataset has a 2-level hierarchical structure with activities nested within pupils, in order to test the Hypotheses 2 and 3, we used hierarchical linear modeling to analyze the data. We used the PASW Statistics Data Editor program for data analysis (Peugh and Enders 2005). Hierarchical linear modeling (HLM) can be used to examine simultaneously the effects of Level 2 (pupils) and Level 1 (episodes within the previous day) variables, which accounts for the dependencies between the day-level reports from the same pupil (Snijders and Bosker 1999). HLM is particularly suitable for longitudinal data analysis, where missing data occurs relatively often, because of its capacity to make use of all available data in the estimation of model parameters (Kwok et al. 2008). It uses maximum likelihood (ML) estimation in the treatment of missing data, which employs both the complete and incomplete data to determine the parameter values that have the highest probability of producing the sample data (Baraldi and Enders 2010).

In order to test the moderation effect of the activity duration in the relationship between pleasantness of the activity and memory-experience gap (Hypothesis 3 ), we recoded the pleasantness of the activity and the duration of the activity into dummy variables. Pleasantness was recoded from the activity-based (episodic) hedonic level of affect. Specifically, activities of which the pleasantness was below person-specific median were categorized as low pleasantness and those above person-specific median as high pleasantness. Similarly, the duration of the activities was recoded into low and high duration: 
On a between-person level, we statistically controlled for age, sex, happiness during past month, number of activities reported, total time active during the day. On a within-person level, we statistically controlled for chronological order in the sequence of activities during the day.

\section{$7 \quad$ RESULTS}

\subsection{Descriptive Statistics}

First, we present the descriptive statistics in order to illustrate the nature of our participants' reports. As can be seen in Table 1, reported numbers of activities pupils engaged in the previous day ranged from 5 to $28(\mathrm{M}=13.89 ; S D=6.12)$. The reported hours being active per day ranged from 1 to 24 , with $13.14 \mathrm{~h}$ on average $(S D=4.08)$.

The mean and the standard deviations are also presented in Table 1, which shows that, when using global assessments, pupils reported high levels of happiness, both during past month $(\mathrm{M}=7.34 ; S D=1.79)$, and yesterday $(\mathrm{M}=7.43 ; S D=1.83)$. The global retrospective estimate of happiness during past month was not significantly higher than retrospective estimate of yesterday $(\mathrm{t}(351)=1.07 ; p=0.28)$. However, when using episodic assessments (DRM), pupils reported moderate levels of happiness $(\mathrm{M}=6.76 ; S D=2.31)$ (Figs. 3 and 4$)$.

\subsection{Hypotheses Testing}

Hypothesis 1. Before testing the first hypothesis, the episodic (activity-based) happiness was duration-weighted. More precisely, we calculated average happiness during daily activities by multiplying the happiness ratings in each activity by the proportion of one's waking hours the activity occupied and adding these products together. We computed memory-experience gap score in order to investigate the differences between the reconstructed rating of global happiness during the previous days and averaged ratings of episodic happiness based on daily activities.

As can be seen in Table 2, and in line with our first hypothesis, the one-sample $t$ test confirmed that the memory-experience gap on a between person-level for happiness ratings is positive and significantly different from zero $(\mathrm{t}(350)=8.11 ; p<0.001)$. Hence, global estimates of yesterday's affect tend to be somewhat more positive than average episodic assessment of the same day. However, the average difference was small $(\mathrm{M}=0.79 ; S D=1.82)$. Figure 3 presents the distribution of the memory-experience gap according to its size and valence, and it demonstrates that the deviation is not only to the positive, but quite often also to the negative.

We examined the variability of the memory-experience gap across the two levels (between-person, and within-person). Of the total variance, $33.7 \%$ was between pupils $(2.085 /(2.085+4.106))$, and $66.3 \%$ was on the activity (within-pupils) level $(4.106 /(2.085+4.106))$, which demonstrated that there is enough variability on each level to conduct multilevel analyses.

To test our hypotheses, we started with a Null model that included the intercept as the only predictor and memory-experience gap on a within-person level as the outcome variable. In Model 1, we entered control variables: age, sex, happiness during past month, number of activities reported, and total time active during the day as Level 2 control variables, and measurement occasion as Level 1 control variable.

Results in Model 1 reveal that age, sex, number of activities reported or total time spent active were not significantly related to memory-experience gap on within- person. Hedonic level during past month related positively to memory-experience gap on the activity level, whereas measurement occasion related negatively to the memory-experience gap on an activity level. In 
Model 2, we added activity duration and pleasantness of activity as predictors. In Model 3, we entered the interaction term between the activity duration on the one hand and the hedonic valence of affect on the other hand. Table 3 illustrates the findings for each of the Models. We tested the improvement of each model over the previous one by computing the differences of the respective $\log$ likelihood statistic $-2 * \log$ and submitting this difference to a chi ${ }^{2}$-test. Each nested model showed an improved model fit. Model 1 was compared to the Null (intercept only) model (A-2loglik $=453.59$, Adf $=6, p<.001)$; Model 2 was compared to Model 1 (A-2loglik $=$ 4928.07, Adf $=2, p<.001$ ); and Model 3 was compared to Model 2 (A-2loglik = 8.24, Adf $=1, p<.01)$.

Hypothesis 2. As can be seen in Table 3, Model 2 showed that hedonic valence of the activities was significantly and negatively related to the memory- experience gap on the within-person level. In other words, the less pleasant pupils felt during specific activity, the larger the gap between the episodic and the overall experience. These results indicated that hedonic valence is significant aspect of affective experiences recall processes because they showed that less pleasant activities tended to be more "distant" from the overall experience than the more pleasant activities tended to. That confirmed our Hypothesis 2.

Hypothesis 3. Hypotheses 3 stated that the pleasantness of the activities moderates the relationship between activity duration and the memory-experience gap on the activity level. Model 3 showed that the interaction pattern between pleasantness of the activities on the one hand, and activity duration on the other hand, was significant. The interaction pattern is graphically displayed in Fig. 5. Figure 5 shows that when an activity is rated as less pleasant (below personal median), the size of the memory-experience gap on activity level increases as the time spent in the activity increases. However, when an activity was rated as more pleasant (above personal median), the size of the memory-experience gap on an activity level decreased as the activity duration increased.

\section{DISCUSSION}

The broad goal of this study was to get more insight into the happiness measurement issues among adolescents. The analysis presented within this study contributes to the existing literature in several ways. First, our results indicate that there is a memory-experience gap in adolescents' happiness reports, which points out to the limitations of commonly used global retrospective happiness measures.

Second, the study provided support for the hypothesis that the memory-experience gap would be larger for less pleasant affective states. These results suggest that the fading affect bias represents a useful theoretical framework that partially explains the memory-experience gap. Third, in this study we present a specific episodic multi-moment happiness assessment method (Yesterdays' Diary, a modified version of the Day Reconstruction Method; Kahneman et al. 2004), which has proven to be a useful and valuable methodology for capturing within-person fluctuations of hedonic level of affect among early adolescents. 
Finally, our study makes a clear distinction between levels of analysis. Specifically, happiness associated with daily activities conceptualized as an indicator of momentary wellbeing is a transient variable. Hence, the use of diary methodology enabled us to analyze fine grained relationships between the duration of yesterdays' activities, the hedonic level of affect related to those activities and the size of the memory-experience gap on a within- person level.

Furthermore, day reconstruction method reduced biases related to global measures of happiness. The findings are discussed in more detail below, together with the strengths and limitations of this study.

\subsection{Memory-Experience Gap: Are Global Estimates of Happiness Too Rosy?}

The results of our study reveal that the memory-experience gap for happiness ratings in early adolescents follows similar patterns to those found in adult population (Miron-Shatz et al. 2009). When asked how they felt yesterday in the overall, pupils tend to overestimate the pleasantness of their affect on the average. In other words, their global yesterdays' happiness reports are higher than their averaged activity-based happiness ratings.

We also aimed to examine what contributes to the memory-experience gap. There are at least three things we can attribute the memory-experience gap to: random measurement error, retrospective bias, as well as method artifacts. The random measurement errors refer to the various factors that influence the happiness reports and are out of our control. The method artifact is another aspect of the memory-experience gap that should be noted. Specifically, the responses for the global retrospective happiness measures that were available for boys and girls were whole numbers, whereas the average happiness rating obtained from episodic measures was a decimal number. In that way, method artifact contributes to the memory-experience gap at least to a small extent.

According to previous studies and theoretical considerations, the largest part of the memory-experience gap could be attributed to the retrospective bias. Specifically, accessibility model of emotion report (Robinson and Clore 2002) posits that retrospective global happiness reports are based on semantic memory. For example, when asked how they typically feel during a specific activity, people tend to express their general beliefs about the activity to arrive at an assessment.

However, the actual experience of happiness is not prominently present in retrospective global happiness reports because the experience itself is gone, and people have to reconstruct it from memory, which makes that type of assessment more prone to retrospective biases (Robinson and Clore 2002). In contrast, when people report on their recently experienced happiness, the affects themselves are more easily accessible because they draw from their episode memory. This, in turn, enables more accurate reports on the basis of experiential information.

\subsection{What Drives the Memory-Experience Gap? The Role of Activity Duration and Hedonic Valence of Affect During the Activities}

In order to examine what factors contribute to the memory-experience gap, in this study we also looked at the within-person fluctuation in the gap. Based on the existing literature, we analyzed the role of the duration of yesterdays' activities and the hedonic level of affect related to those activities for the size of the gap. Our data analysis revealed that longer duration of affect states does not contribute to increased accuracy of retrospective assessment in itself, which is consistent with previous findings (e.g., Fredrickson 2003; Izard 2002). Rather, as our findings suggest, hedonic valence of affect seems to play a crucial role, with highly pleasant states being better recalled in comparison to less pleasant affect states. 
Moreover, we examined if memory-experience gap could be partially explained with the interaction between the activity duration and the activities' hedonic level of affect on the memory-experience gap. The results confirmed our expectations and showed that in making overall retrospective estimates of their happiness throughout the day, pupils seem to overestimate the impact of the short episodes of pleasant activities, while at the same time they underestimate the impact of longer episodes of unpleasant activities. In that way, shorter pleasurable activities are better recalled, indicating that highly pleasant affect fades less over time as compared to unpleasant affect. These findings fit the concept of the fading affect bias (Walker et al. 2003).

Walker et al. (2003) emphasize that this fading affect bias might actually represent a healthy coping processes. Specifically, these findings can be conceptualized within the framework of the mobilization-minimization hypothesis (Taylor 1991), which states that when a person experiences a negative event, mechanisms of minimization and mobilization ofresources are activated. People tend to mobilize various resources to cope with the immediate consequences of the event, and at the same time, they also tend to minimize the impact of the event. Such minimization occurs because people are generally motivated to view their life in a relatively positive light (Gilbert et al. 1998; Walker et al. 2003; Wilson et al. 2000). Hence, the memory-experience gap might actually represent much more than retrospective bias: The memory-experience gap might also reflect the way early adolescents keep the memories of their experiences in a positive light.

\subsection{Limitations}

It should be noted that this approach has some limitations. In this study, we refer to the episodic assessments of happiness as experienced happiness, while in fact those are retrospective reports of very recent episodes. However, we justify our approach by emphasizing the previous research evidence that showed substantial concordance between reports obtained via the day reconstruction method and those obtained in real-time, such as using the experience sampling method (e.g., Dockray et al. 2010; Kahneman et al. 2004; Stone et al. 2006).

Moreover, the memory-experience gap between reports of how happy one feels (affective component of happiness) and how satisfied on is with his or her life happy one is (cognitive component of happiness) is likely to be even greater. Yet, since this study did not involve a cognitive measure of happiness we cannot demonstrate that.

Finally, we also take note on the peak-end rule in affective experiences recall. Specifically, peak-end rule represents the tendency of people to evaluate certain kinds of past affective experience by referring to just a few selected moments, usually the one that contained the most intensely experienced affect, and the one that ended the experience (Fredrickson 2000; Kahneman et al. 1993; Redelmeier et al. 2003). Hence, there is a possibility that peak-end rule might have contributed to the MEGs in our study.

However, our study focused primarily on the investigation of the differences between experiences of pupils' lives and pupils' overall memories of those experiences. We particularly examined the role of hedonic valence of affect in shaping the MEG. In that way, examining the peak-end rule was somewhat beyond the scope of this paper

Moreover, although the peak-end rule has been shown to be a robust tendency applicable to wide range of affective events (for a review see Fredrickson 2000), it was most often related to affective episodes with specific features. The episodes under investigations were typically clearly bounded, completed, were passively endured and were not considered a means to some other end. These features are mostly not applicable to the episodes in our study because the majority of episodes in our study were temporally divided, and, as Frederickson (2000) points out, peak and end rule is not expected to have substantive contributions to temporal episodes (Ariely and Carmon 2000; Barrett 1997). 
Nevertheless, this is an important area that requires further research, particularly in the population of early adolescents. Future studies should explore the degree to which MEG in happiness reports is attributable to the peak-end rule among early adolescents.

\section{CONCLUSIONS AND IMPLICATIONS FOR FUTURE STUDIES}

Children and young people's well-being is fundamental to that of society as a whole. Promoting well-being among children and adolescents is not only vital in order for to have a good childhood, but also as a firm basis for their future well-being as adults (Rees et al. 2010, 2012). Indeed, in recent years, child well-being has become a priority for the European political agenda (Bradshaw and Richardson 2009; UNICEF 2007). However, when it comes to identifying, monitoring and attempting to enhance child well-being, the fundamental challenge is to measure the well-being accurately. In other words, if we do not measure the well-being in a precise and reliable way, we will not be able to monitor it or to enhance it, which is the main goal of children wellbeing research.

Given this context, our study contributes to research on the validity of children and adolescents' well-being indicators because it demonstrated that there is a memory- experience gap in happiness reports of early adolescents: Pupils tend to overestimate their happiness level when asked with a global question, even when the reports refer to how happy one felt. The findings revealed that the size of the gap can, in part, be explained with the hedonic level of affect, with pleasant affect tending to be overestimated and negative to be underestimated.

Altogether, these results have implications for measuring children and adolescents' wellbeing because they showed that global retrospective estimates may not be optimal choice when the research goal is to get more detailed insight into how happy adolescents feel, rather, episodic multi-moment assessment should be used. Thus, if the research uses the global retrospective happiness self-estimates, it is advisable to subtract about $5 \%$ of the scale range.

\section{Acknowledgments}

The data reported in this paper are from a larger project "Should Happiness be taught at school? The effect of "Lessons in Happiness" on measures of well-being and academic performance for pupils aged thirteen at Dutch secondary schools" conducted by Jacqueline Boerefijn (2010). Information is available at http://worlddatabaseofhappiness.eur.nl/hap_bib/freetexts/boerefijn_j_2010.pdf. 


\section{Figure 1}

Global happiness assessment for two time-frames. How happy did you feel yesterday?

How happy did you feel during past month?

How happy did you feel yesterday?

\begin{tabular}{|l|l|l|l|l|l|l|l|l|l|l}
\hline$\because$ & $\ddots$ & $\ddots$ & $\ddots$ & $\ddots$ & $\ddots$ & $\ddots$ & $\ddots$ & $\ddots$ & $\ddots$ & $\ddots$ \\
\hline 0 & 1 & 2 & 3 & 4 & 5 & 6 & 7 & 8 & 9 & 10 \\
\hline
\end{tabular}

How happy did you feel during past month?

\begin{tabular}{|c|c|c|c|c|c|c|c|c|c|c|}
\hline$\ddot{8}$ & 8 & 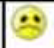 & $\ddot{\theta}$ & $\because$ & $\because$ & $\ddot{*}$ & $\ddot{\theta}$ & $\ddot{*}$ & $\ddot{*}$ & $\ddot{\theta}$ \\
\hline 0 & 1 & 2 & 3 & 4 & 5 & 6 & 7 & 8 & 9 & 10 \\
\hline
\end{tabular}

Figure 2

Episodic happiness assessment. How happy did you feel during that activity?

How happy did you feel during that activity?

\begin{tabular}{|l|l|l|l|l|l|l|l|l|l|l|}
\hline$\because$ & $\ddots$ & $\ddots$ & $\ddots$ & $\ddots$ & $\ddots$ & $\ddots$ & $\ddots$ & $\ddots$ & $\ddots$ & $\Theta$ \\
\hline 0 & 1 & 2 & 3 & 4 & 5 & 6 & 7 & 8 & 9 & 10 \\
\hline
\end{tabular}




\section{Figure 3}

The distribution of the memory-experience gap in happiness (hedonic level of affect) ratings.

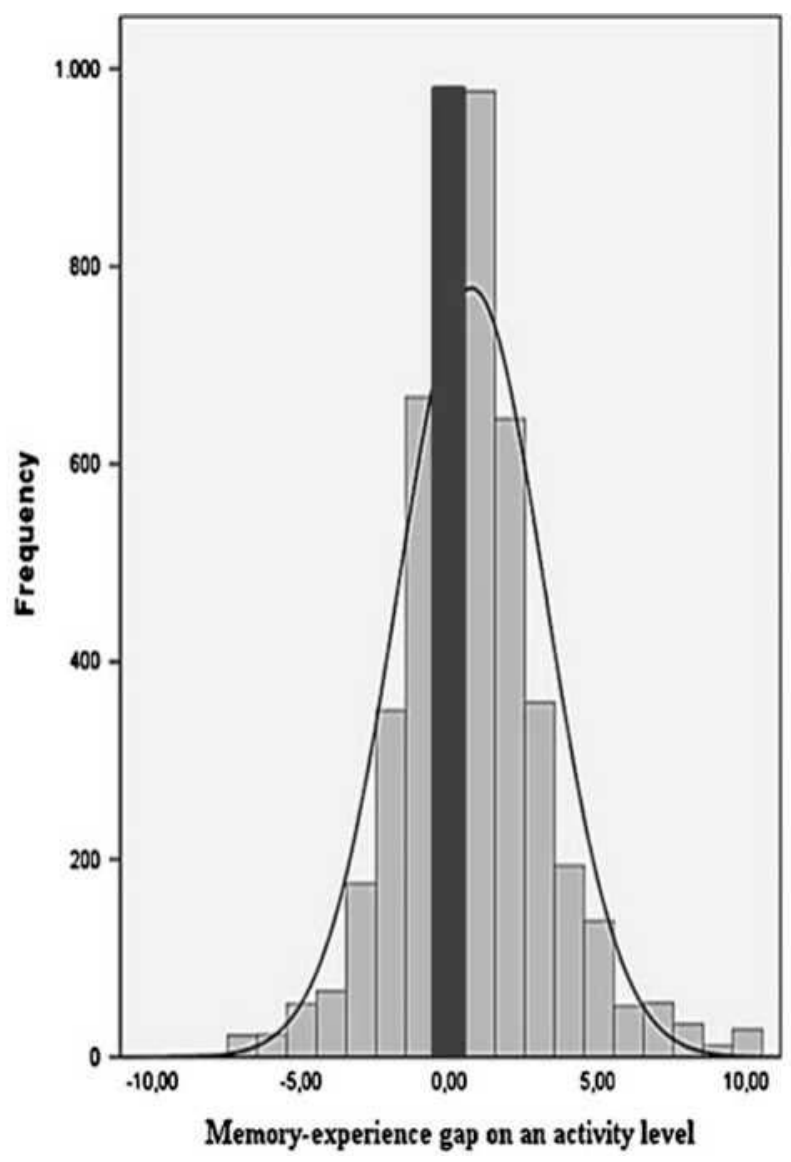




\section{Figure 4}

Happiness indicators comparison

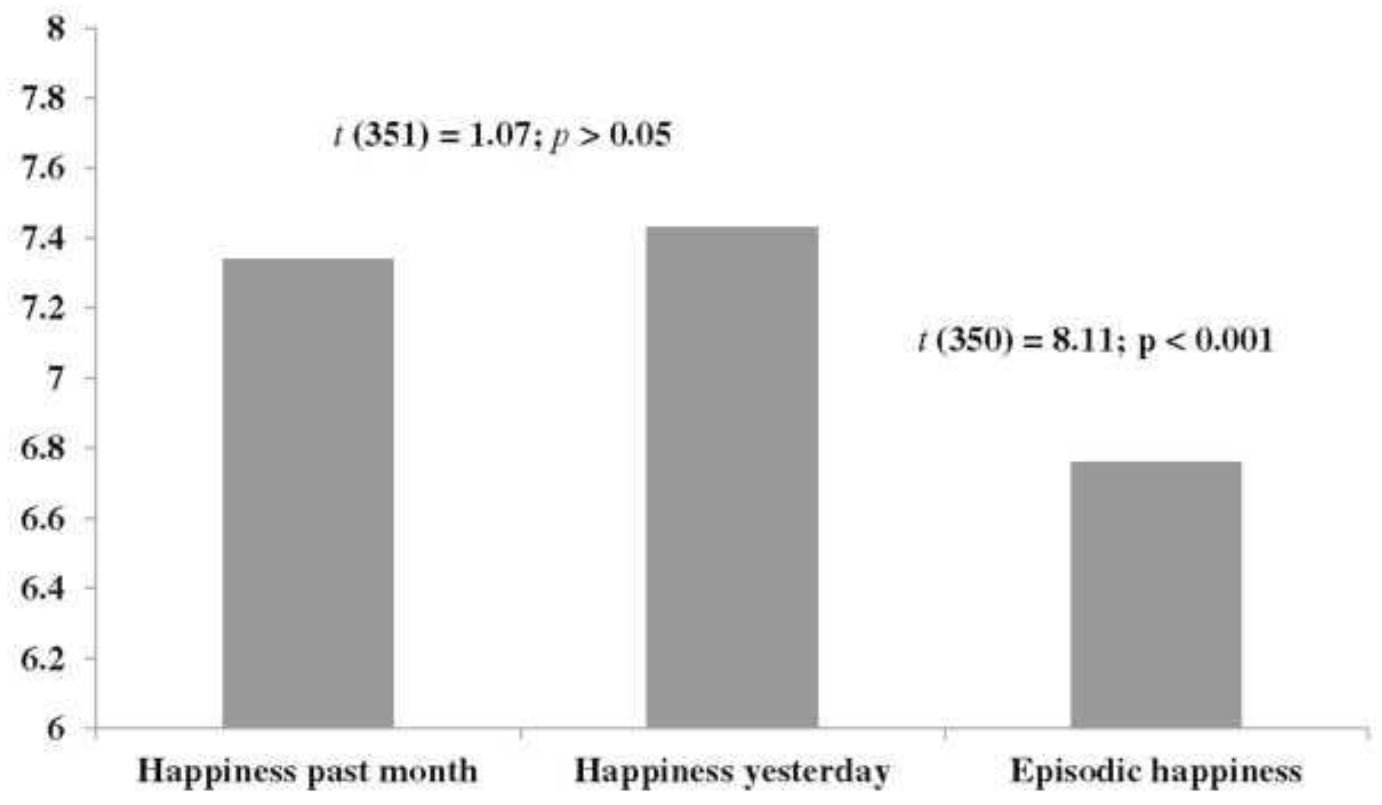




\section{Figure 5}

Interaction effect of hedonic valence of the activity on the relationship between activity duration and memory-experience gap.

Low $=$ below person-specific median; High $=$ above person-specific median

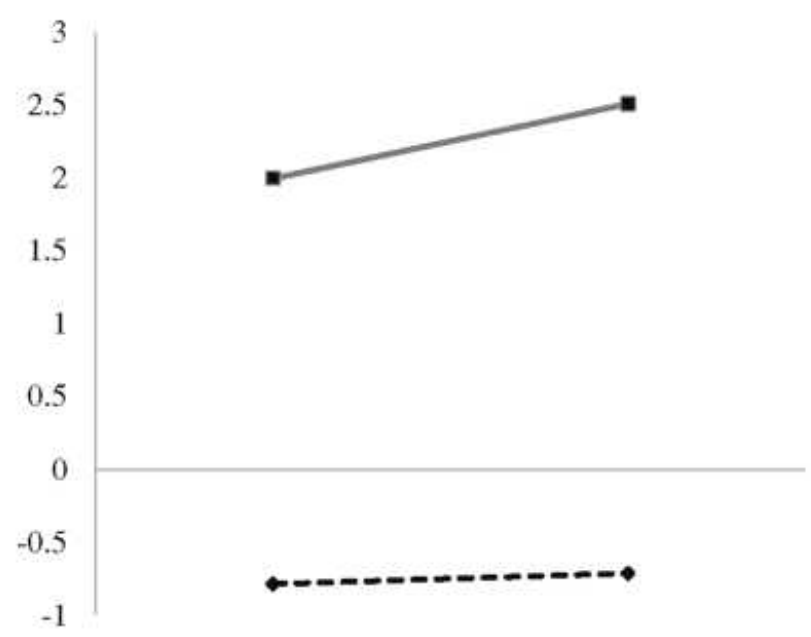

$\rightarrow$ - Low hedonic valence

$\rightarrow-$ High hedonic valence

Duration of activity 
Table 1 Descriptive information for the main variables $(\mathrm{N}=352)$

\begin{tabular}{lll}
\hline Variable & Mean & (SD \\
\hline Number of activities reported (DRM) & 13.89 & $(6.1$ \\
Active hours per day (DRM) & 13.14 & $(4.0$ \\
Global self-reported happiness during past month & 7.34 & $(1.7$ \\
Global self-reported happiness yesterday & 7.43 & $(1.8$ \\
Episodic (activity-based) happiness-Hedonic & 6.76 & $(2.3$ \\
\hline
\end{tabular}

Table 2 Memory experience gap $(\#=352)$

\begin{tabular}{lll}
\hline Variable & Mean (SD) & $\mathrm{t}$ test \\
\hline $\begin{array}{l}\text { Memory-experience gap between- } \\
\text { person level }\end{array}$ & $0.79(1.82)$ & $811^{* * *}$ \\
$\begin{array}{l}\text { Memory-experience gap within- } \\
\text { person level }\end{array}$ & $0.70(2.48)$ & $19.684^{* * * *}$ \\
$* * * p<0.001$ & &
\end{tabular}


Table 3 Multilevel estimates for 2-level models predicting memory-experience gap, N=352

\begin{tabular}{|c|c|c|c|c|c|c|c|c|c|c|c|c|}
\hline & \multicolumn{3}{|c|}{ Null-model } & \multicolumn{3}{|l|}{ Model 1} & \multicolumn{3}{|l|}{ Model 2} & \multicolumn{3}{|l|}{ Model 3} \\
\hline & Estimate & SE & $\mathrm{t}$ & Estimate & $\mathrm{SE}$ & $\mathrm{t}$ & Estimate & $\mathrm{SE}$ & $\mathrm{t}$ & Estimate & SE & $\mathrm{t}$ \\
\hline Constant & 0.744 & 0.084 & $8.891 * * *$ & 2.043 & 1.442 & 1.416 & 7.755 & 1.448 & $5.355^{* * *}$ & 7.610 & 1.450 & $5.247 * * *$ \\
\hline Chronological order & & & & -0.080 & 0.004 & $-20.577 * * *$ & -0.03 & 0.003 & $-8.085^{* * *}$ & -0.026 & 0.003 & $-8.180 * * *$ \\
\hline Age & & & & -0.166 & 0.094 & -1.759 & -0.276 & 0.095 & $-2.902 * *$ & -0.276 & 0.095 & $-2.901 * *$ \\
\hline Gender & & & & -0.142 & 0.159 & -0.895 & -0.075 & 0.163 & -0.463 & -0.076 & 0.162 & -0.468 \\
\hline Happy past month & & & & 0.284 & 0.044 & $6.494 * * *$ & 0.284 & 0.045 & $6.342 * * *$ & 0.285 & 0.044 & $6.347 * * *$ \\
\hline Number of activities & & & & 0.010 & 0.015 & 0.648 & -0.031 & 0.016 & $-2.007^{*}$ & -0.032 & 0.015 & $-2.028^{*}$ \\
\hline Time active & & & & -0.004 & 0.001 & -1.158 & 0.001 & 0.001 & 0.521 & 0.001 & 0.001 & 0.571 \\
\hline Activity duration & & & & & & & -0.002 & 0.001 & $-6.627 * * *$ & 0.001 & 0.001 & 0.710 \\
\hline Hedonic valence & & & & & & & -3.066 & 0.042 & $-73.256 * * *$ & -2.976 & 0.052 & $-56.782 * * *$ \\
\hline Activity duration $\mathrm{X}$ & & & & & & & & & & -0.003 & 0.001 & $-2.873 * *$ \\
\hline \multicolumn{13}{|l|}{ Hedonic valence } \\
\hline-2 Log Likelihood & & 21278.350 & & & 20824.764 & & & 15896.691 & & & 15888.449 & \\
\hline Diff-2 Log & & & & & $453.586^{* * *}$ & & & $4928.073 * * *$ & & & $8.242 * * *$ & \\
\hline Df & & & & & 6 & & & 2 & & & 1 & \\
\hline Level 1 variance & & $4.106(0.087)$ & & & $\begin{array}{l}3.752 \\
\quad(0.079199)\end{array}$ & & & $1.632(0.036)$ & & & $1.629(0.036)$ & \\
\hline Level 2 variance & & $2.085(0.186)$ & & & $\begin{array}{l}1.796 \\
\quad(0.161872)\end{array}$ & & & $2.008(0.168)$ & & & $2.012(0.168)$ & \\
\hline
\end{tabular}

${ }^{*} \mathrm{p}<0.05 ; * * \mathrm{p}<0.01 ; * * * \mathrm{p}<0.001$ 


\section{REFERENCES}

Ariely, D. (1998).

Combining experiences over time: the effects of duration, intensity changes and on-line measurements on retrospective pain evaluations.

Journal of Behavioral Decision Making, 11, 19-45.

Ariely, D., \& Carmon, Z. (2000).

Gestalt characteristics of experiences: the defining features of summarized events.

Journal of Behavioral Decision Making, 13, 191-201.

Baraldi, A. N., \& Enders, C. K. (2010).

An introduction to modern missing data analyses.

Journal of School Psychology, 48(1), 5-37.

Barrett, L. F. (1997).

The relationships among momentary emotion experiences, personality descriptions, and retrospective ratings of emotion.

Personality and Social Psychology Bulletin, 23, 1100-1110.

Ben-Arieh, A. (2008).

The child indicators movement: past, present, and future.

Child Indicators Research,3-16.

Ben-Arieh, A., Kaufman, H. N., Andrews, B. A., Goerge, R., Lee, B. J., \& Aber, J. L. (2001). Measuring and monitoring children's well being.

Dordrecht: Kluwer.

Braam, H., Tan, S., Wentink, M., Bergsma, A., \& Boerefijn, J. (2008).

Lessen in Geluk.

Utrecht: Verwey- Jonker Instituut.

Bradshaw, J., \& Richardson, D. (2009).

An index of child well-being in Europe.

Child Indicators Research, 2(3), 319-351.

Boerefijn, J. (2010).

Should Happiness be taught at school? The effect of "Lessons in Happiness" on measures of well-being and academic performance for pupils aged thirteen at Dutch secondary schools.

Working Paper, Verwey-Jonker Instituut: Utrecht, Netherlands.

Ciarrochi, J., Heaven, P. C. L., \& Supavadeeprasit, S. (2008).

The link between emotion identification skills and socio-emotional functioning in early adolescence: a 1-year longitudinal study.

Journal of Adolescence, 31(5), 565-582. 
Dahl, R. E. (2004).

Adolescent brain development: a period of vulnerabilities and opportunities.

Keynote address. Annals of the New York Academy of Sciences, 1021(1), 1-22.

Diener, E., \& Tay, L. (2013).

Review of the Day Reconstruction Method (DRM).

Social Indicators Research, 1-13.

Dockray, S., Grant, N., Stone, A. A., Kahneman, D., Wardle, J., \& Steptoe, A. (2010). A comparison of affect ratings obtained with ecological momentary assessment and the Day Reconstruction Method.

Social Indicators Research, 99, 269-283.

Fitness, J., \& Fletcher, G. J. (1993).

Love, hate, anger, and jealousy in close relationships: a prototype and cognitive appraisal analysis.

Journal of Personality and Social Psychology, 65(5), 942.

Fredrickson, B. L. (2000).

Extracting meaning from past affective experiences: the importance of peaks, ends, and specific emotions.

Cognition \& Emotion, 14(4), 577-606.

Fredrickson, B. L. (2003).

The value of positive emotions: the emerging science of positive psychology is coming to understand why it's good to feel good.

American Scientist, 91, 330-335.

Gibbons, J. A., Lee, S. A., \& Walker, W. R. (2011).

The fading affect bias begins within 12 hours and persists for 3 months.

Applied Cognitive Psychology, 25(4), 663-672.

Gilbert, D. T., Pinel, E. C., Wilson, T. D., Blumberg, S. J., \& Wheatley, T. P. (1998).

Immune neglect: a source of durability bias in affective forecasting.

Journal of Personality and Social Psychology, 75, 617-638.

Gilman, R. S., \& Huebner, E. S. (2000).

Review of life satisfaction measures for adolescents.

Behavior Change, 17, 178-195.

Gilman, R., \& Huebner, E. S. (2003).

A review of life satisfaction research with children and youth.

School Psychology Quarterly, 18, 192-205.

Huebner, E. S. (2004).

Research on assessment of life satisfaction of children and adolescents.

Social Indicators Research, 66(1), 3-33. 
Huebner, E. S., Drane, W., \& Valois, R. F. (2000).

Levels and demographic correlates of adolescent life satisfaction reports.

School Psychology International, 21, 281-292.

Huebner, E. S., Valois, R. F., Paxton, R. J., \& Drane, J. W. (2006).

Middle school students' perceptions of quality of life.

Journal of Happiness Studies, 6, 15-24.

Izard, C. E. (2002).

Translating emotion theory and research into preventive interventions.

Psychological Bulletin, 128(5), 796-824.

Kahneman, D., \& Deaton, A. (2010).

High income improves evaluation of life but not emotional wellbeing.

Proceedings of the National Academy of Sciences, 107(38), 16489-16493.

Kahneman, D., \& Krueger, A. B. (2006).

Developments in the measurement of subjective well-being.

Journal of Economic Perspectives, 20(1), 3-24.

Kahneman, D., Fredrickson, B. L., Schrieber, C., \& Redelmeier, D. A. (1993).

When more pain is preferred to less: adding a better end.

Psychological Science, 8, 255-258.

Kahneman, D., Krueger, A. B., Schkade, D., Schwarz, N., \& Stone, A. (2004).

Toward national well-being accounts.

American Economic Review, 94(2), 429-434.

Kemp, S., Burt, C. D. B., \& Furneaux, L. (2008).

A test ofthe peak-end rule with extended autobiographical events.

Memory \& Cognition, 36(1), 132-138.

Krueger, A. B., \& Schkade, D. A. (2008).

The reliability of subjective well-being measures.

Journal of Public Economics, 92(8-9), 1833-1845.

Kwok, O. M., Underhill, A. T., Berry, J. W., Luo, W., Elliott, T. R., \& Yoon, M. (2008).

Analyzing longitudinal data with multilevel models: an example with individuals living with lower extremity intraarticular fractures.

Rehabilitation Psychology, 53(3), 370.

Larson, R. W., Moneta, G., Richards, M. H., \& Wilson, S. (2002).

Continuity, stability, and change in daily emotional experience across adolescence.

Child Development, 7, 1151-1165.

Lee, M. (2003).

Daily contextual variations in levels of adolescent happiness.

The Korean Journal of Development Psychology, 16, 193-209. 
McAuley, C. (2012).

Child well-being in the UK: children's views of families.

The Politicization of Parenthood, 127-138.

Miron-Shatz, T., Stone, A., \& Kahneman, D. (2009).

Memories of yesterday's emotions: does the valence of experience affect the memory-experience gap?

Emotion, 9(6), 885-891.

Pavot, W., \& Diener, E. (2008).

The Satisfaction with Life Scale and the emerging construct of life satisfaction.

The Journal of Positive Psychology, 3(2), 137-152.

Peugh, J. L., \& Enders, C. K. (2005).

Using the SPSS mixed procedure to fit cross-sectional and longitudinal multilevel models.

Educational and Psychological Measurement, 65, 717-741.

Redelmeier, D. A., Katz, J., \& Kahneman, D. (2003).

Memories of colonoscopy: a randomized trial.

Pain, 104(1-2), 187-194.

Rees, G., Bradshaw, J., Goswami, H., \& Keung, H. (2010).

Understanding children's well-being: A national survey of young people's well-being.

London: The Children's Society.

Rees, G., Goswami, H., Pople, L., Bradshaw, J., Keung, A., \& Main, G. (2012).

The good childhood report 2012: A review of our children's well-being.

London: The Children's Society.

Robinson, M. D., \& Clore, G. L. (2002).

Belief and feeling: evidence for an accessibility model of emotional self-report.

Psychological Bulletin, 128(6), 934-960.

Schimmack, U. (2003).

Affect measurement in experience sampling research.

Journal of Happiness Studies, 4(1), 79-106.

Schimmack, U., Oishi, S., Diener, E., \& Suh, E. (2000).

Facets of affective experiences: a framework for investigations of trait affect.

Personality and Social Psychology Bulletin, 26, 655-668.

Schwarz, N., Kahneman, D., Xu, J., Belli, R., Stafford, F., \& Alwin, D. (2009).

Global and episodic reports of hedonic experience.

Using calendar and diary methods in life events research, 157-174.

Scollon, C., Kim-Prieto, C., \& Diener, E. (2009).

Experience sampling: promises and pitfalls, strength and weaknesses.

In E. Diener (Ed.), Assessing well-being vol. 39 (pp. 157-180).

Netherlands: Springer. 
Silk, J. S., Steinberg, L., \& Morris, A. S. (2003).

Adolescents' emotion regulation in daily life: links to depressive symptoms and problem

behavior.

Child Development, 74, 1869-1880.

Snijders, T. A. B., \& Bosker, R. J. (1999).

Multilevel analysis: An introduction to basic and advanced multilevel modeling.

Thousand Oaks: Sage.

Sonnemans, J., \& Frijda, N. H. (1995).

The determinants of subjective emotional intensity.

Cognition \& Emotion, 9(5), 483-506.

Stone, A. A., \& Broderick, J. E. (2007).

Real-time data collection for pain: appraisal and current status.

Pain Medicine, 8, S85-S93.

Stone, A. A., Schwartz, J. E., Schkade, D., Schwarz, N., Krueger, A., \& Kahneman, D. (2006). A population approach to the study of emotion: diurnal rhythms of a working day examined with the day reconstruction method.

Emotion, 6(1), 139-149.

Taylor, S. E. (1991).

Asymmetrical effects of positive and negative events: the mobilization-minimization hypothesis. Psychological Bulletin, 110, 67-85.

Thompson, C. P., Skowronski, J. J., Larsen, S. F., \& Betz, A. L. (1996). Autobiographical memory: Remembering what and remembering when.

New York: Erlbaum.

Todd, M., Tennen, H., Carney, M. A., Armeli, S., \& Affleck, G. (2004).

Do we know how we cope? Relating daily coping reports to global and time-limited retrospective assessments.

Journal of Personality and Social Psychology, 86, 310-319.

UNICEF. (2007).

Child poverty in perspective: An overview of child well-being in rich countries,

Innocenti report card 7. Florence: UNICEF.

Veenhoven, R. (1984).

Conditions of happiness.

Dordrecht: D. Reidel Publishing.

Veenhoven, R. (2009).

How do we assess how happy we are?

In A. K. Dutt \& B. Radcliff (Eds.), Happiness, economics and politics: Towards a multidisciplinary approach. Chapter 3 (pp. 45-69).

Cheltenham: Edward Elger Publishers. 
Veenhoven, R. (2011).

Bibliography of Happiness,

World Database of Happiness, Erasmus University Rotterdam, The Netherlands.

Assessed on 1-11-2011 at: http://worlddatabaseofhappiness.eur.nl/hap_bib/bib_fp.php.

Verduyn, P., Delvaux, E., Van Coillie, H., Tuerlinckx, F., \& Van Mechelen, I. (2009).

Predicting the duration of emotional experience: two experience sampling studies.

Emotion, 9, 83-91.

Verduyn, P., Van Mechelen, I., \& Tuerlinckx, F. (2011).

The relation between event processing and the duration of emotional experience.

Emotion, 11, 20-28.

Verduyn, P., Tuerlinckx, F., \& Van Gorp, K. (2012).

Measuring the duration of emotional experience: The influence of actual duration and response format.

Quality \& Quantity, 1-11.

Walker, W. R., \& Skowronski, J. J. (2009).

The fading affect bias: but what the hell is it for?

Applied Cognitive Psychology, 23(8), 1122-1136.

Walker, W. R., Vogl, R. J., \& Thompson, C. P. (1997).

Autobiographical memory: unpleasantness fades faster than pleasantness over time.

Applied Cognitive Psychology, 11, 399-413.

Walker, W. R., Skowronski, J. J., \& Thompson, C. P. (2003).

Life is pleasant - and memory helps to keep it that way!

Review of General Psychology, 7, 203-210.

Wilson, T. D., Wheatley, T., Meyers, J. M., Gilbert, D. T., \& Axsom, D. (2000).

Focalism: a source of durability bias in affective forecasting.

Journal of Personality and Social Psychology, 78, 821-836.

Wirtz, D., Kruger, J., Scollon, C. N., \& Diener, E. (2003).

What to do on spring break?

Psychological Science (Wiley-Blackwell), 14(5), 520-524.

Yurgelun-Todd, D. (2007).

Emotional and cognitive changes during adolescence.

Current Opinion in Neurobiology, 17(2), 251-257. 